\title{
ATIVIDADE EXPERIMENTAL PROBLEMATIZADA (AEP): Discussões Pedagógicas e Didáticas de uma Asserção de Sistematização Voltada ao Ensino Experimental das Ciências
}

\author{
André Luís Silva da Silva ${ }^{1}$ \\ Paulo Rogério Garcez de Moura² \\ José Cláudio Del Pino 3
}

\begin{abstract}
RESUMO
Consideradas as interfaces entre discussões pedagógicas e didáticas (praxiológicas) como oportunas à qualidade do processo de ensino, aqui configuradas como constituintes de uma Cultura Educacional, tendo em vista a garantia dos meios e métodos para fins de aprendizagem, neste artigo é apresentada a Atividade Experimental Problematizada (AEP), caracterizada como uma proposta de sistematização teórico-metodológica voltada ao ensino das Ciências, nas particularidades da experimentação. Para tanto, sob o âmbito de uma pesquisa teórica amparada por fundamentos bibliográficos qualitativos, em caráter propositivo e reflexivo, discute-se a asserção da AEP, cuja tessitura articula pressupostos próprios da Teoria da Aprendizagem Significativa e da Epistemologia de Thomas Kuhn, pretendendo-se, como resultado do processo da instrução em ambientes formais de ensino, a produção de interpretações, significados e sentidos em Ciências, a partir dos quais deverão ser desenvolvidos modos mais complexos e satisfatórios de reflexão e posicionamento individual em sociedade.
\end{abstract}

Palavras-chave: Ensino de ciências; experimentação; cultura educacional.

\section{PROBLEMATED EXPERIMENTAL ACTIVITY (PEA): PEDAGOGICAL AND DIDACTIC DISCUSSIONS OF A SYSTEMATIZATION ASSERTION AIMED AT EXPERIMENTAL TEACHING OF SCIENCES}

\begin{abstract}
Considering the interfaces between pedagogical and didactic (praxiological) discussions as opportune to the quality of the teaching process, here configured as constituents of an Educational Culture, with a view to guaranteeing the means and methods for learning purposes, this article presents the Problematized Experimental Activity (PEA), characterized as a proposal for theoretical-methodological systematization aimed at teaching Science, in the particularities of experimentation. Therefore, under the scope of a theoretical research supported by qualitative bibliographic foundations, in a propositional and reflexive nature, the PEA's assertion is discussed, whose texture articulates presuppositions of the Meaningful Learning Theory and of Thomas Kuhn's Epistemology, intending, as a result of the instruction process in formal teaching environments, the production of interpretations, meanings and senses in Science, from which more complex and satisfying ways of reflection and individual positioning in society should be developed.
\end{abstract}

Keywords: Science teaching; experimentation; educational culture.

RECEBIDO EM: 5/7/2021

ACEITO EM: $14 / 8 / 2021$

\footnotetext{
1 Autor correspondente. Universidade Federal do Pampa. Av. Pedro Anunciação Filho, n. 111 - Vila Batista. Caçapava do Sul/RS, Brasil. CEP 98030-410. http://lattes.cnpq.br/0808253492421363. https://orcid.org/0000-0002-8245-9389. andresilva@unipampa.edu.br.

2 Universidade Federal do Espírito Santo - Ufes. Vitória/ES, Brasil. http://lattes.cnpq.br/9815585530252572. https://orcid.org/0000-00032659-5383.

3 Universidade Federal do Rio Grande do Sul - UFRGS. Porto Alegre/RS, Brasil. http://lattes.cnpq.br/2152799270731771. https://orcid. org/0000-0002-8321-9774.
} 


\section{A TÍTULO DE INTRODUÇãO: Perspectivas Pedagógicas e Didáticas Circunscritas à AEP}

Ao se considerar a apropriação docente de fundamentos teórico-metodológicos de aspectos pedagógico e didático como um imperativo à qualidade de sua práxis, mesmo que estes sejam tomados como eixos concomitantes e não concorrentes, verificam-se identidades e natureza distintas, cabendo um entendimento particularizado e aprofundado de cada. E isso mesmo que se deseje chegar a um olhar comum, capaz de configurar a ação docente como um meio processual ao favorecimento de aprendizagens significativas. Assim sendo, pretende-se neste artigo identificar e caracterizar, em um primeiro momento, algumas dessas bases, tomando-se como cenário a metodologia da experimentação e suas potenciais contribuições aos saberes e fazeres circunscritos às ações do ensinar e do aprender. Em seguida, busca-se apresentar a AEP como uma sistemática capaz de potencializar subsídios da experimentação à transposição do ensino em aprendizagem, isto é, à apropriação de significados psicológicos pelo sujeito aprendiz a partir da logicidade e coerência dos objetos de conhecimento promovida pelo professor.

Tendo em vista discussões de âmbito pedagógico, remete-se atenção às atribuições dos alunos, isto é, aprender, em outros termos, desenvolver significados psicológicos, com relação aos objetos de conhecimento (de Ciências) que Ihes são ensinados. Neste domínio, bases teóricas circunscritas à aprendizagem ganham destaque, pois buscam elencar condições à aprendizagem, suas premissas e consequências, atentando para teses voltadas ao próprio processo da aprendizagem. Nesse aspecto, um planejamento instrucional que contemple metas próprias e específicas à apropriação dos objetos de conhecimento e, com isso, coloque em pauta perspectivas concretas de reflexão sobre múltiplos interesses e possibilidades constitutivas e emergentes de determinadas aprendizagens, é salutar ao estabelecimento das linhas de raciocínio demandadas ao aluno para que aprenda, de fato. Com isso, certamente, estratégias de ensino ganham relevância.

Nessa acepção, pode-se cogitar que, ao se balizar a práxis docente por fundamentos próprios à aprendizagem, isto é, pelos pressupostos de uma Teoria de Aprendizagem, deseja-se direcionar procedimentos de ensino às possibilidades de desenvolvimento de novos saberes, ou, poder-se-ia afirmar, às bases que estruturam e legitimam uma Teoria Educacional, capaz de qualificar os meios do ensino e com isso favorecer os fins da aprendizagem. Desse modo, constrói-se um vetor de origem pedagógica que aponta ao sentido didático.

Com relação às perspectivas didáticas, costumeiramente faz-se menção a um planejamento instrucional, em âmbito de conteúdos e de suas estratégias de mediação, sob um olhar atento à atuação docente, o ensinar. Mantido este enfoque, as intervenções docentes, isto é, os métodos empregados para que o processo do ensino resulte em múltiplas possibilidades de aprendizagem, ganham relevância, tomando-os como base do planejamento instrucional. Ao se particularizar a Ciência como cenário, além de suas áreas de conhecimento e dos conteúdos curriculares próprios a elas, cabe uma atenção solene à imagem científica desejável de apresentação, trabalho e compreensão, a qual 
é fomentada pela concepção docente, mesmo que de modo implícito e despercebido. Reitera-se, no entanto, neste espaço, menção à relação estabelecida entre o processo do ensinar, pautado por objetos de conhecimento e estratégias didáticas capazes de favorecer o aprender, a partir de um planejamento instrucional que considere propósitos inteligíveis à instrução, para além de aplicações pontuais e fins peremptórios.

Com base em argumentos de Sacristán e Gómez (1998), o conjunto de metas e de métodos adjacentes aos contextos de ensino-aprendizagem configura-se como uma Cultura Educacional, levando em conta a associação orgânica e substantiva entre tais argumentos. Com a apresentação desta rede teórico-metodológica está comprometida a Figura 1, trazendo a AEP como proposta articuladora. Com isso, mostram-se conceitos que levam a princípios aqui estabelecidos como foco analítico, os quais serão aprofundados e desmembrados em novos, adjacentes e paralelos, paulatinamente, conforme 0 avanço das discussões.

Figura 1 - Articulação entre conceitos e princípios configuradores de uma Cultura Educacional

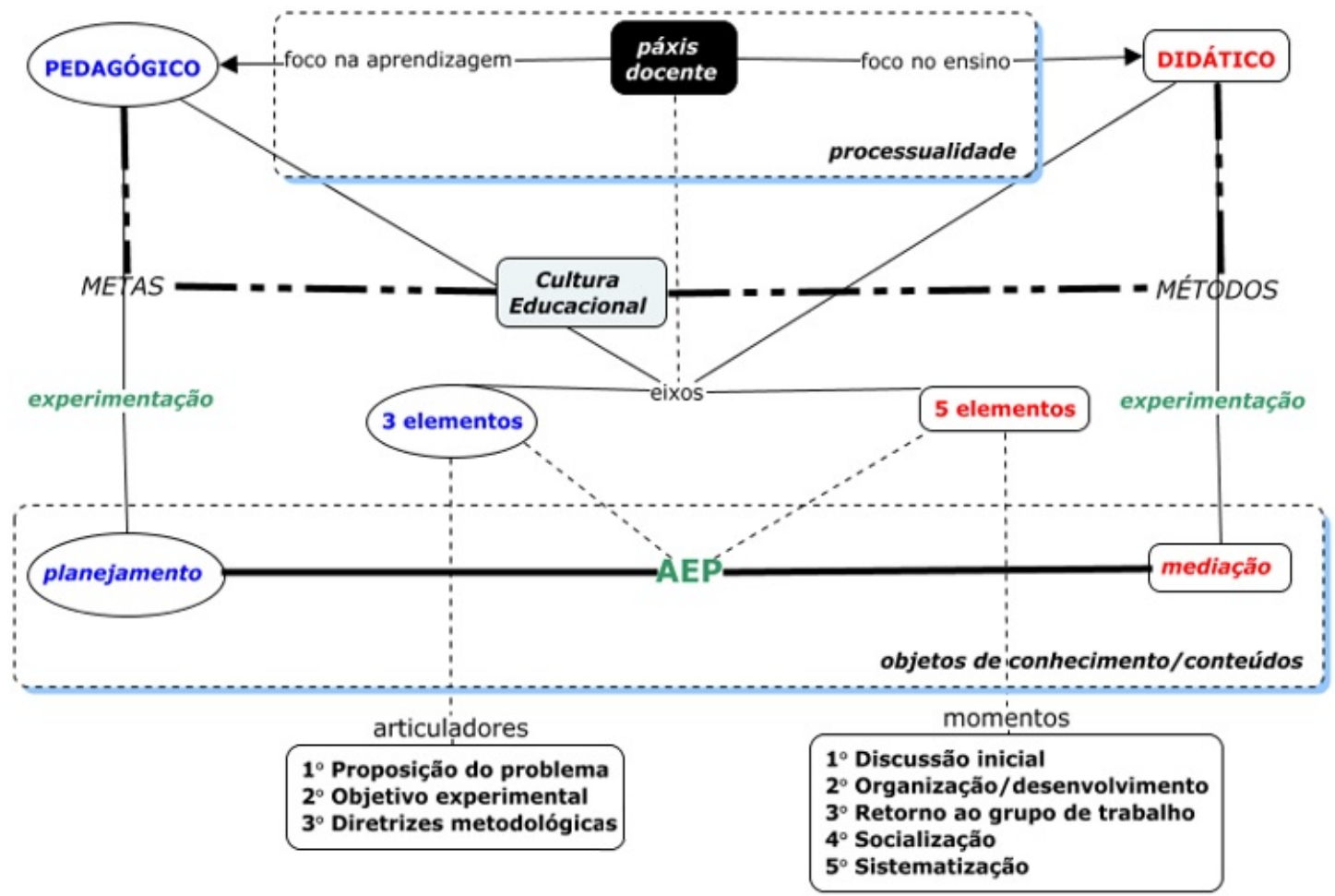

Fonte: Própria.

Englobando princípios teórico-metodológicas aderentes aos eixos pedagógico e didático, sob as concepções explicitadas, bem como amparando-se por diretrizes próprias oriundas da Teoria da Aprendizagem Significativa e da Epistemologia de Thomas Kuhn, a AEP é aqui apresentada como uma proposta ao ensino experimental das Ciências, comprometida à aprendizagem de seus conceitos/princípios/teorias aptos às transformações ou transposições necessárias à tomada de decisão cientificamente fundamentada e socialmente comprometida. Mesmo entendida e defendida como um método de ensino, considerações referentes às metas adjacentes ao planejamento e mediação da AEP são imprescindíveis, tendo-se como elementos conectores os conteúdos de ensino/objetos de conhecimento integrantes das subáreas das ciências. 
É perceptível que são as pretensões, as intencionalidades, as metas estabelecidas que irão nortear as decisões curriculares, com estas últimas constituindo-se como definidoras de planejamentos e de intervenções. É plenamente razoável, portanto, que se definam tais propósitos, e mesmo que sejam expostos aos alunos os resultados dessas definições, quando for inviável compartilhar com eles tais decisões. Ao não se fazer isso, isto é, não produzir e socializar junto aos envolvidos o que se espera como resultado (e/ ou produto de aplicação) da instrução, os próprios métodos aplicados, mesmo que potencialmente valiosos sob o ponto de vista da autonomia e da criticidade, são prejudicados. Pozo e Crespo (2009, p. 64) reforçam esta ideia, ao apontarem que "[...] pode-se reduzir os problemas a exercícios, as estratégias a rotinas e técnicas, o saber fazer ao saber repetir", ao não se ter clareza dos propósitos pedagógicos que subjazem à didática instrucional.

Nesse contexto, o que se pode satisfatoriamente apontar como constitutivo do propósito essencial do ensino ou da Educação em Ciências? Entre variadas linhas teóricas, propósitos de Alfabetização Científica ganham relevância, ao se atentar na busca pela construção de sentido ao mundo, com compreensão satisfatória de seus princípios e fenômenos. Outra diretriz das quais se poderia valer é de natureza cognitiva, ao se almejar, a partir da instrução de natureza científica, o desenvolvimento de modos mais complexos e satisfatórios de reflexão e posicionamento individual. Além desses, certamente, outros exemplos poderiam ser revelados, bem como outras linhas teóricas subjacentes (FOUREZ, 1995; NOVAK; GOWIN, 1984).

Parte-se também do pressuposto de que o Ensino de Ciências deve propiciar aos alunos entendimentos duradouros e transferíveis a outros contextos, para além da sala de aula e dos demais ambientes formais de ensino. É sobremaneira desejável que os sujeitos sejam capazes de descontextualizar seus saberes científicos. Ao professor, impõe-se tornar mais transferível e generalizável os conteúdos trabalhados, por meio do uso de estratégias desafiadoras de mediação e criação de situações midiáticas concretas. Por outro lado, espera-se que o aluno seja capaz de aplicar os conteúdos tratados nas aulas de Ciências em seu próprio meio, transferindo-os de dimensões escolares às cotidianas e, com isso, fundamentando cientificamente suas decisões individuais e participações e envolvimentos coletivos (BERWIG, 2018).

Retornando à AEP: sendo esta concebida como uma proposta de sistematização teórico-metodológica voltada para o ensino experimental das Ciências, tal asserção está materializada em duas obras bibliográficas. Na primeira, Silva e Nogara (2018) apresentam exemplificações de AEPs no contexto do ensino da Química; na segunda, Silva e Moura (2018) a estendem às demais Ciências, fundamentando-a pedagógico-epistemologicamente. Da mesma forma, desde 2015 artigos versam sobre a temática (SILVA; MOURA; DEL PINO, 2015; 2017; 2018; SILVA et al. 2019). Posto isso, passar-se-á a fundamentos próprios da AEP, bem como acerca das diretrizes que os subjazem: elementos conceituais/proposicionais da Teoria da Aprendizagem Significativa e da Epistemologia de Thomas Kuhn.

\section{CONCEPÇÕES, MEIOS E PROPÓSITOS DA AEP}

A AEP configura-se como um processo de ensino-aprendizagem, nas particularidades das Ciências experimentais, que se desenvolve a partir da demarcação de um problema de natureza teórica, isto é, configura-se como uma prática que objetiva a busca 
por uma solução justificável a dada situação-problema. Na conjuntura de uma AEP o próprio problema apresentado ao aluno deve despertar nele sua motivação, interesse, desafio intelectual e capacidade de discussão e de articulação de ideias, promovendo a autoconfiança necessária para que busque apresentar explicações idiossincráticas aos fenômenos/situações tratados.

Para que essa metodologia de ação, todavia, possa lograr êxito, em termos do favorecimento de aprendizagens, o professor não deve fornecer (e tampouco esperar por) respostas prontas, previamente determinadas, mas processualmente novos questionamentos e desafios, no intuito de levar o aluno a formular e a reformular seu próprio entendimento. Nessa dinâmica, o professor assume a função de questionador, conduzindo perguntas e propondo problemas aos seus alunos, auxiliando-os na exploração, desenvolvimento e adequação constante de suas próprias concepções, para que eles venham a sugerir hipóteses e justificativas às aparentes inconsistências com as quais se deparam (GALIAZZI; GONÇALVES, 2004; HODSON, 1994).

O ensino experimental fundamentado na busca por solução de problemas articula-se à característica que a vida cotidiana tem de apresentar desafios, e incentiva os alunos a aperfeiçoarem seus métodos e habilidades heurísticas, tornando-os capazes de coletar, sistematizar, analisar, compreender e comunicar dados e informações, e de operar neles transformações visando a novos conhecimentos para responder a novos desafios. Nessa acepção, ensinar a

[...] resolver problemas não consiste somente em dotar os alunos de habilidades e estratégias eficazes, mas também em criar neles o hábito e a atitude de enfrentar a aprendizagem como um problema para o qual deve ser encontrada uma resposta. Não é uma questão de somente ensinar a resolver problemas, mas também de ensinar a propor problemas para si mesmo, a transformar a realidade em um problema que mereça ser questionado e estudado (POZO, 1998, p. 15).

A partir dessa concepção, por meio da AEP busca-se propiciar aos alunos sua capacidade de autonomia, ao realizarem registros, discutirem resultados, levantarem hipóteses, avaliarem possíveis explicações e discutirem, entre seus pares e com o professor, métodos, justificativas e abrangências circunscritas ao experimento. Essa atividade, contudo, deve ser metodizada, visando à promoção de uma análise reflexiva desde sua origem. Sob essa ótica, a função do professor não mais se configura como centralizador e fornecedor das respostas e das certezas; antes, deve problematizar com seus alunos suas concepções e observações, as amplas leituras do experimento, auxiliando-os a reconhecer a necessidade premente de outros saberes/fazeres e, por conseguinte, a importância do diálogo reflexivo e da pesquisa orientada na busca por uma coerente interpretação das observações empíricas (BERWIG, 2018).

O aporte teórico da proposta da AEP caracteriza os alunos como sujeitos que desenvolvem conhecimentos em um processo no qual o professor assume e desempenha o papel de orientador, cuja genuinidade é específica, mas abrangente. Cabe assim a constante supervalorização das perguntas em relação às suas possíveis respostas, em um movimento pedagógico dialético e dinâmico. Em conformidade com o que destaca Santos (2008, p. 126), “[...] o papel do professor não está em revelar a realidade aos educandos, mas em ajudá-los a desvendar a realidade por si sós". Sob esse enfoque, 
torna-se oportuna a compreensão de que o objetivo da experimentação não deve ser a formação ou doutrinação do aluno a pensar/agir de modo padronizado, mas despertar nele uma concepção crítica e reflexiva da realidade, bem como sua capacidade de tomadas de decisão, que o auxilie, tanto cognitivamente na compreensão do fenômeno em si como socialmente, na transposição que poderá fazer dos saberes tratados. Com isso, métodos, resultados e conclusões heterogêneos devem ser incentivados, uma vez que, de acordo com Latour e Woolgar (1997, p. 61), à luz empírica, "[...] os fenômenos dependem do material, eles são totalmente constituídos pelos elementos utilizados no laboratório".

Isso posto, considera-se a possibilidade dos alunos em estabelecer conexões próprias entre a atividade realizada experimentalmente e os aportes teóricos, conceituais e proposicionais correlacionados e fundantes aos temas tratados. Constituindo-se "[...] a ciência uma construção humana, deve-se reconhecer que no fazer ciência se desenvolve um processo de representação da realidade em que predominam acordos simbólicos e linguísticos num exercício continuado de discursos mentais" (GIORDAN, 1999, p. 46).

A inserção em um laboratório de Ciências, tendo em vista uma abordagem e processualidade pedagógico-científica problematizada pode, por si, estimular a curiosidade investigativa dos alunos quando eles são desafiados cognitivamente, contudo não é imprescindível. Tampouco a mera inclusão do aluno em ambientes de atividades práticas representa uma fonte suficiente de motivação e/ou meio que favoreça a compreensão do que é tratado. É necessário que se estabeleça um confronto cognitivo com problemas propostos e a constante reflexão das ideias reveladas (GUIMARÃES, 2009). Nessa direção, o modo pelo qual a atividade experimental é planejada, proposta e conduzida, as reflexões a partir dela originadas e a associação às suas bases conteudinais se sobrepõem à própria metodologia da experimentação. Além disso, nenhuma atividade experimental isoladamente logra desenvolver os efeitos esperados em termos de ensino e aprendizagem, tendo em vista a promoção de autonomia intelectual dos sujeitos nela envolvidos (HODSON, 1994).

\section{ESTRUTURA TEÓRICO-METODOLÓGICA DA AEP}

Ao se compreender a imprescindibilidade de uma fundamentação teórico-metodológica a toda intervenção de ensino com fins de aprendizagem, propõe-se como e denomina-se de AEP uma estratégia didático-pedagógica voltada ao ensino experimental das Ciências, configurada em dois principais eixos, um de natureza teórica e outro metodológica, associativos e potencialmente indissociáveis. Mostra-se no Quadro 1, em síntese, seus fundamentos denotativos, tratados como eixos teórico (e seus articuladores) e metodológico (e seus momentos). 
Quadro 1 - Elementos denotativos da AEP: teóricos e metodológicos

\begin{tabular}{|c|c|}
\hline \multicolumn{2}{|c|}{ eixos } \\
\hline TEÓRICO & METODOLÓGICO \\
\hline $\begin{array}{l}\text { a. Proposição de problema } \\
\text { b. Objetivo experimental } \\
\text { c. Diretrizes metodológicas }\end{array}$ & $\begin{array}{c}\text { i. Discussão prévia } \\
\text { ii. Organização/desenvolvimento } \\
\text { iii. Retorno ao grupo de trabalho } \\
\text { iv. Socialização } \\
\text { v. Sistematização }\end{array}$ \\
\hline
\end{tabular}

Fonte: SILVA; MOURA (2018).

Considera-se como eixo teórico da AEP, em seus elementos articuladores, uma configuração que se estrutura a partir da demarcação, elucidação e proposição de um problema de natureza teórica, isto é, uma AEP conforma-se teoricamente como uma estratégia de busca por solução a dada situação-problema. A partir de então são elaborados um objetivo experimental, tratando-se, sob uma perspectiva abrangente, daquilo que se espera desenvolver empiricamente em termos de produto/ação experimental, e diretrizes metodológicas, orientações às ações que potencialmente resultarão no referido produto/ação experimental de interesse. Sendo assim, a proposta de ensino experimental cunhada como AEP propõe uma articulação entre objetivo experimental e diretrizes metodológicas, a partir da proposição e da análise crítica de um problema, para o qual se buscará uma possibilidade de solução, neste caso, por vias empíricas.

Essa tessitura, representada na Figura 2, consubstancia-se na Epistemologia de Thomas Kuhn (ETK), tendo em vista os seus aspectos teóricos que defendem um conhecimento científico não determinista, construído socialmente e favorecido por uma adaptação teoria-experimento e por um protocolo empírico, aqui demarcado como guia de planejamento experimental (KUHN, 1998, 2000).

Figura 2 - Articuladores teóricos para a proposta de AEP; subsídios epistemológicos

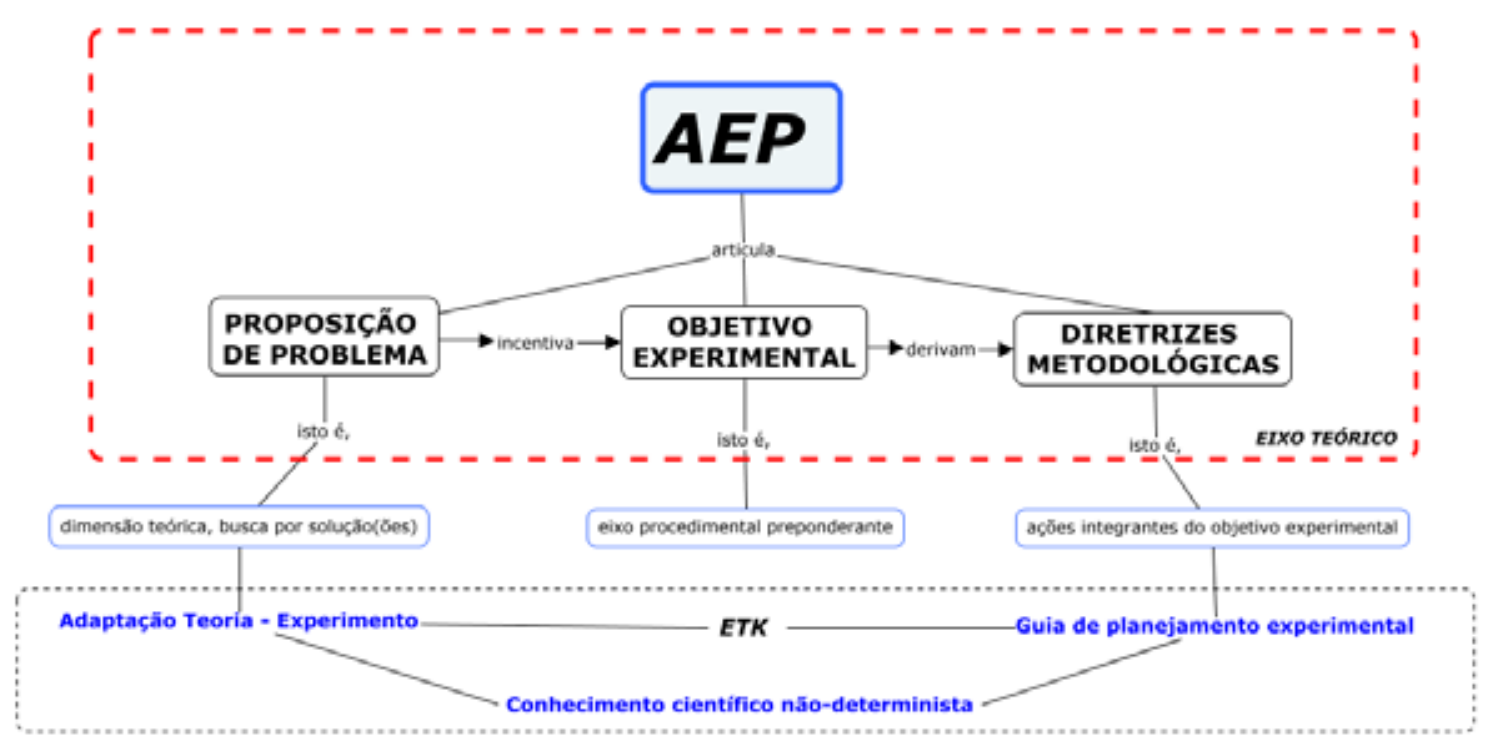

Fonte: SILVA; MOURA (2018). 
Com base nos subsídios epistemológicos subjacentes à AEP, tem-se na ETK aportes teóricos que defendem a experimentação como uma atividade capaz de favorecer uma compreensão da Ciência sob vieses epistemologicamente contemporâneos, isto é, capazes de apresentá-la como socialmente construída e hermeneuticamente aberta, substanciadas por fatores objetivos, subjetivos e intersubjetivos adjacentes às atividades desenvolvidas.

De encontro a isso verifica-se que o conhecimento científico ainda é, nos dias atuais, concebido por muitos de seus atores como infalível, transparecendo a ideia de que somente o que é "cientificamente comprovado" merece atenção e pode trazer benefícios à população (CHALMERS, 1999), contudo

[...] as escolhas, as possibilidades, a incerteza, são ao mesmo tempo propriedades do universo e (também) são próprias da existência humana. Elas abrem novas perspectivas para a ciência e uma nova racionalidade, aonde a verdade científica não mais é sinônimo de certo, ou determinado, e aonde o incerto e o indeterminado não estão baseados na ignorância, no desconhecimento. [...] A marca do nosso tempo é uma ciência em que o ser e a estabilidade deram passagem para a evolução e a mudança (PRIGOGINE, 2002, p. 21).

Nesse intento, consideram-se concepções epistemológicas capazes de romper com uma tradição de Ciência empirista-indutivista imprescindíveis a uma orientação pedagógica capaz de subsidiar seus processos de ensino-aprendizagem, tendo em vista as amplas possibilidades de relações epistemologia-pedagogia. Ao se considerar que as concepções de Ciências que os professores dispõem implicam, explicita ou implicitamente, o modo como planejam e ensinam, em relação às atividades práticas-laboratoriais, em não raras vezes verifica-se que

[...] os estudantes executam tarefas sem saber para onde caminham e que respostas hão de dar e a quê. Parece - e parece-lhes - que os conhecimentos surgem claros, óbvios e não precisam ser interrogados e têm uma resposta que surge natural. Essa é a pior maneira de usar um bom instrumento de aprendizagem (PRAIA; CACHAPUZ; GIL-PÉREZ, 2002, p. 130-131).

Em contrapartida, a concepção de uma Ciência permissiva a compreensões psicológicas (próprias, idiossincráticas) favorece uma práxis capaz de aproximar seus fundamentos de seus aprendizes e articular teoria e experimento. Para Van Fraassen (1980, p. 74), “[...] a teoria tem um duplo papel na experimentação: formulação de questões a serem respondidas de uma maneira sistemática e como guia no planejamento de experimentos para responder a essas questões". Sendo assim, a AEP aceita esse paradigma, vinculando, de modo imperativo, um planejamento teórico à experimentação.

Com referência aos elementos articuladores, componentes do eixo teórico da AEP, de modo sucinto, instaura-se o planejamento da atividade pela proposição de um problema, de natureza teórica, articulável a unidades conteudinais de interesse. Esse problema requer para seu desenvolvimento um objetivo experimental, do qual derivarão proposituras orientadoras às ações, denominadas de diretrizes metodológicas. 0 planejamento, elaboração, apresentação e mediação de tais eixos configuram-se em atribuições do professor, propositor e organizador da atividade prática. Em propósito de 
síntese, mostra-se no Quadro 2 uma discussão específica de caracterização do problema, objetivo e diretrizes, elementos teóricos indispensáveis ao planejamento e à sistematização da proposta da AEP.

\section{Quadro 2 - Caracterização do eixo teórico da AEP}

\begin{tabular}{|c|c|}
\hline 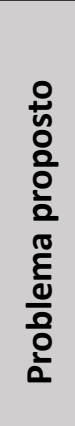 & $\begin{array}{l}\text { O problema que origina a AEP requer a elaboração de uma solução, ou sua derivação } \\
\text { em novos argumentos, distinguindo-se da singularidade de uma pergunta, que gera } \\
\text { a expectativa de uma resposta. Problemas privilegiam processos, remetem ao uso de } \\
\text { estratégias heurísticas, métodos, técnicas próprias da investigação sistêmica, na busca } \\
\text { por uma solução frente a muitas outras que poderiam ser aventadas. Perguntas, por sua } \\
\text { vez, atendem-se ao resultado, aceito ou não aceito, e apontam a um fim. Genuinamente, } \\
\text { um problema atrela-se a uma situação exigente de um maior grau de complexidade, } \\
\text { não se podendo atribuir acerto ou erro tão somente a partir do que dele resulta, tendo } \\
\text { em vista amplas possibilidades metodológicas imbuídas em sua condução, das quais os } \\
\text { resultados dependerão (ECHEVERRÍA; POZO, 1998; SACRISTÁN, 2007). }\end{array}$ \\
\hline 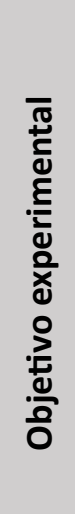 & $\begin{array}{l}\text { Refere-se a propostas de atividades práticas àquilo que centraliza a experimentação, } \\
\text { operacionalmente. Qual técnica é imprescindível à geração de dados, que serão } \\
\text { transformados subjacentemente em resultados e com isso potencialmente oferecerão } \\
\text { subsídios práticos à solução do problema proposto? Ao término dos procedimentos } \\
\text { empíricos, o que se pretende obter/produzir? Que produto/objeto poderá ser gerado? } \\
\text { Pretende, portanto, conduzirossujeitos àgeraçãoderesultados, masnãonecessariamente } \\
\text { à solução do problema proposto, visto que esse deverá ser analisado e compreendido } \\
\text { significativamente para tanto, desde que o problema seja oportuno e congruente a } \\
\text { tal fim. Desse modo, deve servir a um propósito amplo, à busca pela obtenção de um } \\
\text { produto teórico a partir de ações processuais, não levando a soluções previamente } \\
\text { esperadas e tampouco carentes de possibilidades profusas de interpretações, pois um } \\
\text { único fenômeno pode ser interpretado sob muitas vias. }\end{array}$ \\
\hline 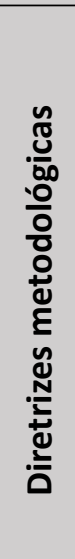 & $\begin{array}{l}\text { Não sob uma tendência prescritiva, mas, reforçando a ideia de orientação procedimental, } \\
\text { as diretrizes metodológicas constituem-se de um protocolo de ações práticas derivadas } \\
\text { do objetivo experimental. Atuam como proposituras orientadoras aos procedimentos a } \\
\text { serem realizados. Não devem ser admitidas como um fator limitador da experimentação; } \\
\text { defende-se aqui que a aprendizagem é reduzida ao se tratar da experimentação sob } \\
\text { vieses observacionais ou procedimentais determinísticos. Tais indicações, contudo, } \\
\text { surgem como uma etapa necessária, a qual oferece o estabelecimento das primeiras } \\
\text { ações e norteia os fazeres gerais. Não se reduzem a imposições, podendo ser alteradas/ } \\
\text { adaptadas a qualquer tempo por professor e/ou alunos, dadas as condições reais. Além } \\
\text { disso, visam à inteligibilidade do objetivo proposto e incentivam uma discussão entre } \\
\text { os integrantes do grupo de trabalho anterior e concomitante às suas ações, fatores } \\
\text { considerados cruciais à organização das ideias individuais e estabelecimento de uma } \\
\text { ação conjunta. }\end{array}$ \\
\hline
\end{tabular}

Fonte: Os autores.

Tendo em vista sua mediação, propõe-se o delineamento da AEP por meio de uma sequência metodológica constituída por cinco etapas, caracterizadas como momentos. Estes têm início por uma discussão introdutória envolvendo professor e alunos; consolidam-se pela materialização de um produto final, desenvolvido por esses alunos. Tais momentos, contudo, são flexíveis e poderão adequar-se aos propósitos específicos e a caracterizações propositais dos sujeitos envolvidos, cabendo sua análise crítica desde o planejamento da atividade, incentivando uma contínua propositura de ações derivadas. 
Esse protocolo metodológico, representado na Figura 3, articula-se à Teoria da Aprendizagem Significativa (TAS), tendo em vista determinados conceitos/princípios dela originários, tais como: estrutura cognitiva específica, material potencialmente significativo e predisposição em aprender, e modos distintos germinadores de aprendizagens, por descoberta e por recepção (AUSUBEL, 2003).

Figura 3 - Momentos metodológicos para a proposta de AEP; subsídios pedagógicos

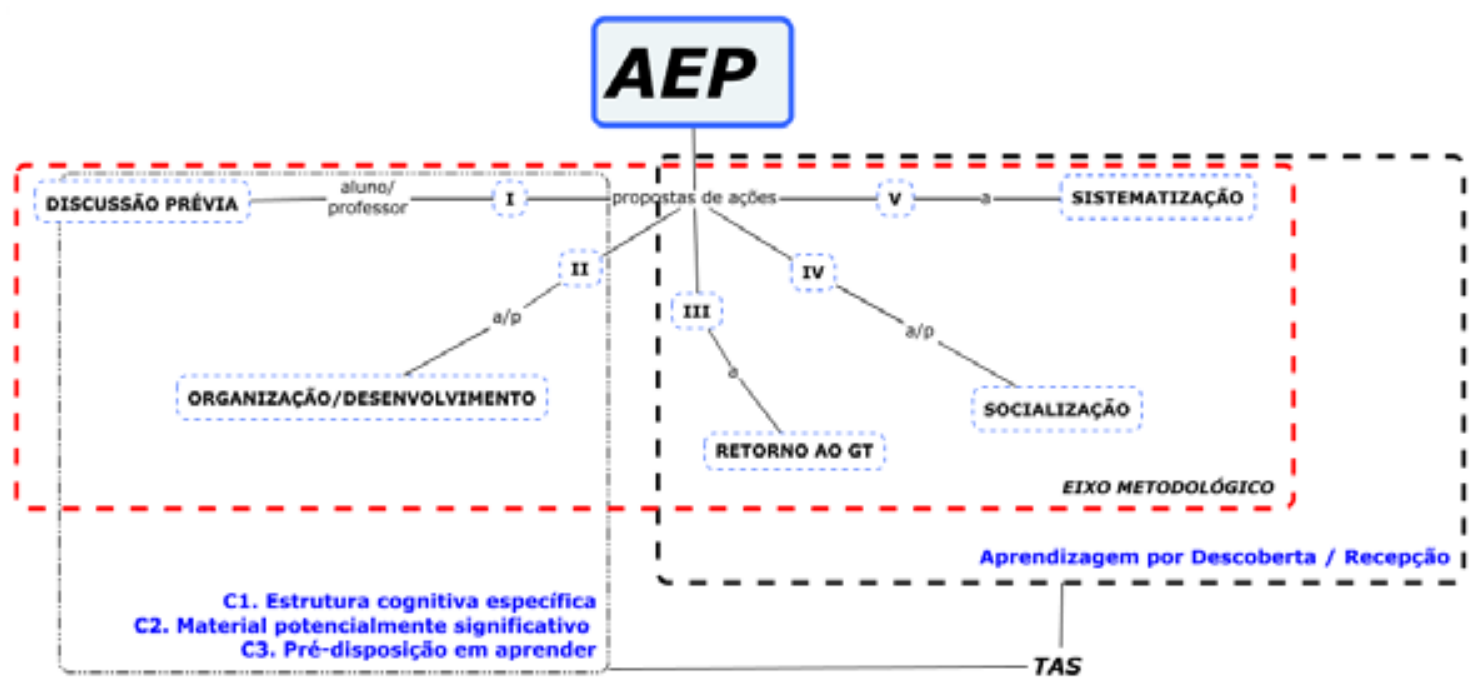

Fonte: SILVA e MOURA (2018).

Com relação aos subsídios pedagógicos subjacentes à AEP, tem-se na TAS fundamentos teórico-metodológicos capazes de caracterizá-la como uma estratégia de ensino com foco na aprendizagem, nas particularidades da experimentação das Ciências. Em seu núcleo central a teoria atrela a aprendizagem a três condições, concomitantes e indissociáveis, sendo elas: (i) a estrutura cognitiva específica, (ii) o material potencialmente significativo e (iii) a predisposição do sujeito em aprender. Em (i), sugere-se que o aprendiz poderá aprender de modo significativo ao relacionar novas informações com seu conhecimento prévio, isto é, ao possuir e/ou desenvolver subsunçores, elementos cognitivos capazes de oferecer significados psicológico e idiossincrático àquilo que lhe é apresentado. Vincula-se em (ii) a abordagem conteudinal sob fundamentos lógico e coerente, isto é, estratégias de ensino utilizadas pelo professor em sua práxis docente. Com relação a (iii), impõe-se a aprendizagem significativa a uma disposição/mobilização própria do sujeito, a qual pode ser favorecida pelos méritos de (i) e (ii), mas não garantida (AUSUBEL, 2003; AUSUBEL; NOVAK; HANESIAN, 1980; MOREIRA, 1983, 2006).

A TAS aponta ainda para possibilidades de aprendizagens significativas por descoberta e por recepção. Na primeira, objetos de aprendizagens não são apresentados aos sujeitos em seu formato final, definitivo, mas são desvendados em caracterizações e propriedades a partir das relações que por/entre eles são estabelecidas. Em uma aprendizagem do segundo tipo, por sua vez, conteúdos curriculares são apresentados aos potenciais aprendizes em seu formato concludente, cabendo a eles a atribuição de significados psicológicos. Nenhum tipo prevalece em mérito, contudo o segundo é mais recorrente em sala de aula ou laboratórios, técnicos ou didáticos (MOREIRA, 2006). 
Considera-se a AEP uma estratégia capaz de encerrar as três condições supracitadas sustentadas na aprendizagem, favorecendo aprendizagens significativas de temáticas científicas, em dados momentos por descoberta, em outros por recepção. Para tanto, um protocolo de ações - uma sequência didática, um plano de ensino - designado neste arcabouço teórico como eixo metodológico, é fundamental.

Variadas são as possibilidades de elaboração de um plano de ensino com centralidade metodológica em seus sujeitos envolvidos, em um encadeamento da experimentação em Ciências. Gandin (1994), Gil (2012), Anastasiou e Alves (2009) afirmam que não há um modelo fixo a ser seguido, mas que uma consistente proposta didática deve oferecer amplas possibilidades de aprendizagem, apresentando variações de recursos metodológicos e de estratégias de ensino. No caso da AEP, consideram-se as ações a seguir, em sua sistematização, como uma estratégia pedagógica condizente aos seus propósitos de estrutura teórica e metodológica a uma aprendizagem capaz de gerar significados, não em um formato de rigidez, mas incentivador de um ensino permissivo de reconfiguração de saberes e reconstrução de significados por seus sujeitos integradores (SOARES; LOGUERCIO, 2017).

Têm-se, com isso, cinco momentos: discussão prévia, organização e desenvolvimento da atividade experimental, retorno ao grupo de trabalho, socialização e sistematização, presumidos como imprescindíveis a uma atividade de ensino que ofereça subsídios metodológicos aos aspectos teóricos da AEP, com base em fundamentos próprios da TAS. Outras ações, entretanto, de natureza complementar ou ampliativa, poderão ser acrescidas, tomando-se como pressuposto suas contribuições à inteligibilidade no que se refere aos objetos/objetivos de aprendizagem e adequação sistêmica do método à práxis do professor, bem como a outros fatores imensuráveis e/ou (inter)subjetivos. Sobre estes cinco momentos, e suas caracterizações e especificidades, detalhes são apresentados no Quadro 3.

\section{Quadro 3 - Caracterização do eixo metodológico da AEP}

\begin{tabular}{|c|c|}
\hline & $\begin{array}{l}\text { Concebendo-se que um processo de aprendizagem, conforme propõe Kuhn (2000), é } \\
\text { desencadeado por uma tensão criativa à ação, originada de um descompasso entre } \\
\text { realidade e finalidade, o qual configura-se como um recurso de significação, conclui-se } \\
\text { que se aprende mais e melhor a partir de algo previamente existente, já caracterizado e } \\
\text { estabelecido cognitivamente. Nesse ínterim, como ação desencadeadora do processo } \\
\text { da AEP, propõe-se uma discussão introdutória, em sala de aula ou laboratório, como } \\
\text { proposta de identificação dos conhecimentos prévios dos alunos sobre as temáticas } \\
\text { principais a serem abordadas. O objetivo central desse momento, em moldes da TAS em } \\
\text { suas conceituações para subsunçores e conhecimento prévio, consiste em apresentar, } \\
\text { identificar e desenvolver saberes com a coparticipação dos alunos (AUSUBEL, 2003, } \\
\text { 1978). }\end{array}$ \\
\hline 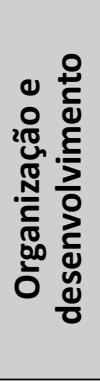 & $\begin{array}{l}\text { Visa à organização procedimental da experimentação. Inicia-se pela proposição } \\
\text { do problema teórico (elaborado, identificado ou selecionado) e de suas derivações } \\
\text { em objetivo experimental e diretrizes metodológicas. Avança à efetivação coletiva } \\
\text { de uma organização ao trabalho experimental, envolvendo a disposição dos alunos } \\
\text { em pequenos grupos, com subsequente recomendação para discussões iniciais em } \\
\text { cada, seguidas pelo levantamento de hipóteses à solução ao problema proposto, } \\
\text { emergentes dos conhecimentos prévios dos alunos. Segue-se ao desenvolvimento da } \\
\text { atividade experimental, quando os alunos realizam a experimentação a partir de seu } \\
\text { entendimento, sob observação e orientação do professor. }\end{array}$ \\
\hline
\end{tabular}


Neste momento pretende-se favorecer a reflexão e discussão intragrupos de trabalho, seguidas pelo arranjo e sistematização das informações registradas. Após a realização da atividade experimental é solicitado aos alunos que retornem ao seu grupo de trabalho para ordenação dos registros que julgarem pertinentes. Nessa fase, passam ao desenvolvimento cognitivo balizador a uma compreensão dos dados experimentais obtidos, a serem transformados em resultados emergentes de uma interpretação conjunta e dialógica, com perspectivas de solução do problema proposto no início da atividade. Ao professor cabe aqui um posicionamento de neutralidade, analisando, in loco, saberes/fazeres decorrentes, mas não intervindo nos caminhos percorridos pelos alunos em vista à solução do problema originário da atividade.

Tendo em vista a premência de uma relação ensino-aprendizagem processual, que subvaloriza os fins e incentiva a busca constante por soluções e por novos questionamentos, o momento da socialização ganha relevância, pois "demonstrará" os caminhos metodológicos seguidos a partir das justificativas que cada grupo utilizará ao defender seus resultados e uma possível solução ao problema desencadeador da AEP. A partir da acareação entre diferentes pontos de vista pode-se seguir a uma possível generalização, tendo em vista os encaminhamentos dados pelo professor. Sendo assim, este momento objetiva incentivar um diálogo entre os diferentes grupos de trabalho, tendo em vista distinções teórico-metodológicas que poderão levar a resultados e a conclusões consideravelmente dessemelhantes. Consiste, portanto, no oferecimento de um espaço-tempo coletivo à troca de ideias referentes aos procedimentos realizados durante a técnica.

Reputa-se a materialização de um produto como uma ação imprescindível à aprendizagem e geração de conhecimentos próprios, particulares, psicológicos. Configura-se como uma atividade que deve apresentar certa individualidade. Pode-

20 se utilizar de material impresso como subsídio teórico, seguido por uma produção textual pelo aluno a partir dos conhecimentos que produziu em torno das informações manipuladas, coletadas e/ou produzidas. Normalmente, após o desenvolvimento de uma técnica experimental, é solicitada a produção de um relatório, desenvolvido por grupo de trabalho. Essa estratégia pode ser mantida, desde que se ofereçam diretrizes à sua elaboração, não no propósito de padronização - uma vez que sua função não é profissionalizante, mas pedagógica - mas no intuito de oferecer aos alunos subsídios quanto a um modo coerente pelo qual poderão apresentar seus resultados e estruturar os produtos de suas observações.

Fonte: Os autores.

Nos entremeios de progresso e desdobramentos dos cinco momentos aludidos, algumas habilidades são favorecidas ao modelo de aluno que se pretende alcançar, tais como: realização de leitura compreensiva, caracterização e domínio de múltiplas imagens circunscritas à Ciência, desenvolvimento de capacidades operatórias e heurísticas, aquisição de uma visão integradora e sistêmica dos objetos de conhecimento trabalhados, qualificação de argumentação, fomento à iniciativa e criatividade, capacidade de pesquisar, acessar e processar informações fundamentadas, otimização plena da capacidade crítica e competência de cooperação e socialização. E, no estabelecimento de uma cultura educacional que privilegie a problematização de concepções e observações, a asserção da AEP é praxiologicamente oportuna, ao ser planejada e mediada a partir de uma situação-problema que busca levar os sujeitos à produção de interpretações, significados e sentidos em Ciências, capacitando-os ao desenvolvimento de modos mais complexos e satisfatórios de reflexão e posicionamento individual. Na perspectiva ainda 
mais particular da experimentação no Ensino de Ciências, tomada aqui como o processo de integração e progressão de conhecimentos empíricos, metodológicos e analíticos em Ciências, ao se dar ênfase na solução de problemas, a transposição de saberes ganha destaque, reforçando a ideia de que se sobrepõe à metodologia da experimentação o modo pelo qual a atividade experimental é planejada, proposta e conduzida, bem como as reflexões a partir dela originadas.

\section{A TÍTULO DE ENCERRAMENTO: Conclusões Provisórias}

Com foco nas discussões particulares à AEP, foram demarcadas neste artigo potenciais contribuições ao processo do ensino, destacando-se a premência de uma mediação didática atenta à aprendizagem, bem como da própria aprendizagem, aqui defendida como propósito pedagógico, com foco nos fatores psicológicos adjacentes ao processo cognitivo de apropriação de conteúdos científicos.

Ao se utilizar da experimentação tendo-se como meta um ensino gerador de aprendizagens significativas, ou intencionado para tal, percebe-se nos entremeios dos procedimentos práticos da AEP múltiplas condições satisfatórias para abordagens e tratamentos aos conteúdos científicos de suporte, além da natureza própria da experimentação como linguagem científica. Costuma-se, nos ambientes formais de ensino, favorecer outras abordagens para temas científicos, como a descritiva, a numérica, a gráfica, por exemplo, em detrimento da experimental, o que por si descaracteriza a Ciência de suas bases genuínas, além de distanciá-la do interesse dos alunos, não raramente ávidos pelos procedimentos empíricos e investigativos. Mesmo ao se assumir a posição de aceite da existência de importantes distinções entre a produção do conhecimento científico e sua aprendizagem, deve-se reconhecer que nos ambientes escolares desenvolvem-se os primeiros contatos dos alunos com uma forma própria de caracterização deste tipo de conhecimento. Sendo assim, abordagens epistemológicas favoráveis a uma percepção não determinista da Ciência, mas dependente de idiossincrasias e aberta às interpretações são fundamentais ao desejável, isto é, à aprendizagem significativa de seus conceitos, princípios e teorias (CACHAPUZ et al., 2011).

Ao denotar o conhecimento científico como articulado ao contexto cotidiano, do qual este é histórica e culturalmente dependente, e nele exerce grande influência transformadora, abrem-se possibilidades cognitivas de conversões lógicas em psicológicas, a partir de uma amplitude de significados. Em acréscimo, o tratamento de conteúdos científicos sob uma perspectiva de construção social, e não como uma apropriação do real, favorece esta apropriação, tendo em vista que integra os sujeitos a um tipo particular de conhecimento, o qual busca o entendimento de seus fundamentos para chegar-se a melhores leituras, às causas e seus efeitos observados.

Tendo em vista o entendimento de que uma cultura educacional é estabelecida ao se considerar seus elementos pedagógicos e didáticos, ou praxiológicos, aqui encadeados pela asserção da AEP, por meio desta, por sua vez, pretende-se, em seu planejamento e mediação, abranger dadas condições permissivas à caracterização de um tratamento científico adjacente à concepção de Ciência pretendida, permitindo que os sujeitos assumam uma posição de destaque, protagonismo e autonomia. Ao abranger 
articuladores e momentos próprios, isto é, uma sistematização organizacional comprometida com um ensino capaz de oportunizar aprendizagens, sob fundamentos da Teoria da Aprendizagem Significativa, e fomentar uma concepção científica sob diretrizes oriundas da Epistemologia de Thomas Kuhn, esta estratégia didático-pedagógica é considerada oportuna para apropriações, aplicações, avaliações e aproximações a variados contextos e realidades educacionais, com expectativa voltada ao ensino e à aprendizagem das Ciências.

\section{REFERÊNCIAS}

ANASTASIOU, L.; ALVES, L. P. Processos de ensinagem na universidade: pressupostos para as estratégias de trabalho em aula. 8. ed. Joinville: Univille, 2009.

AUSUBEL, D. P. Aquisição e retenção de conhecimentos: uma perspectiva cognitiva, Lisboa: Editora Plátano, 2003.

AUSUBEL, D. P. Educational Psychology: a cognitive view. 1. ed. New York: Holt Mc Dougal, 1978.

AUSUBEL, D. P.; NOVAK, J. D.; HANESIAN, H. Psicologia educacional. 2. ed. Rio de Janeiro: Editora Interamericana, 1980.

BERWIG, A. Compreensões sobre tecnologias, ensino e aprendizagem na formação humana. Revista Contexto \& Educação, 33(106), p. 178-197, 2018. DOI: https://doi.org/10.21527/2179-1309.2018.106.178197

CACHAPUZ, A.; GIL-PEREZ, D.; PESSOA DE CARVALHO, A. M.; PRAIA, J.; VILCHES, A. A necessária renovação do ensino das ciências. São Paulo: Cortez Editora, 2011.

CHALMERS, A. F. O que é essa coisa chamada ciência, afinal? São Paulo: Editora Brasiliense, 1999.

ECHEVERRÍA, M. D. P. P.; POZO, J. I. (org.). Aprender a resolver problemas e resolver problemas para aprender. In: POZO, J. I. (ed.). A solução de problemas: aprender a resolver, resolver para aprender. Porto Alegre: Artmed, 1998.

FOUREZ, G. A construção das ciências. São Paulo: Editora Unest, 1995.

GALIAZZI, M. C.; GONÇALVES, F. P. A natureza pedagógica da experimentação: uma pesquisa na licenciatura em química. Química Nova, v. 27, n. 2, p. 326-331, 2004.

GANDIN, D. A prática do planejamento participativo. 2. ed. Petrópolis: Vozes, 1994.

GIL, A. C. Metodologia do ensino superior. 4. ed. São Paulo: Atlas, 2012.

GIORDAN, M. O papel da experimentação no ensino de ciências. Química Nova na Escola, n. 10, p. 43-49, 1999.

GUIMARÃES, C. C. Experimentação no ensino de química: caminhos e descaminhos rumo à aprendizagem significativa. Química Nova na Escola, v. 31, n 3, p. 198-202, 2009.

HODSON, D. Hacia un enfoque más crítico del trabajo de la laboratório. Enseñanza de las Ciencias, v. 12, n. 3, p. 299-313, 1994.

KUHN, T. S. The road since structure. Chicago: The University of Chicago Press, 2000.

KUHN, T. A estrutura das revoluções científicas. 5. ed. São Paulo: Perspectiva, 1998.

LATOUR, B.; WOOLGAR. A vida de laboratório. Rio de Janeiro: Relume Dumará, 1997.

MOREIRA, M. A. A teoria da aprendizagem significativa e sua implementação em sala de aula. Brasília, DF: UnB, 2006.

MOREIRA, M. A. Uma abordagem cognitivista ao ensino de Física: a teoria de aprendizagem de David Ausubel como sistema de referência para a organização do Ensino de Ciências. Porto Alegre: Editora da UFRGS, 1983.

NOVAK, J. D.; GOWIN, D. B. Aprendiendo a aprender. Barcelona: Martínez Roca, 1984.

POZO, J. I. (org.). A solução de problemas: aprender a resolver, resolver para aprender. Porto Alegre: Artmed, 1998.

POZO, J. I.; CRESPO, M. A. G. A aprendizagem e o ensino de ciências: do conhecimento cotidiano ao conhecimento científico. Porto Alegre: Artmed, 2009. 
PRAIA, J. F.; CACHAPUZ, A. F. C.; GIL-PÉREZ, D. Problema, teoria e observação em ciência: para uma reorientação epistemológica da Educação em Ciência. Ciência \& Educação, v. 8, n. 1, p. 127-145, 2002.

PRIGOGINE, I. O fim das certezas: tempo, caos e as leis da natureza. São Paulo: Editora Unesp, 2002.

SACRISTÁN, J. G.; GÓMEZ, A. I. P. Compreender e transformar o ensino. 4. ed. Artmed, 1998.

SACRISTÁN, J. G. A educação que ainda é possível: ensaios sobre uma cultura para a educação. Porto Alegre: Artmed, 2007.

SANTOS, W. L. P. Educação científica humanística em uma perspectiva freireana: resgatando a função do ensino de CTS. Alexandria - Revista de Educação em Ciência e Tecnologia, v. 1, n 1, p. 109-131, 2008.

SILVA, A. L. S.; MOURA, P. R. G.; DEL PINO, J. C. Atividade experimental problematizada: uma proposta de diversificação das atividades para o ensino de ciências. Experiências em Ensino de Ciências, v. 10, n. 3, 2015.

SILVA, A. L. S.; MOURA, P. R. G.; DEL PINO, J. C. Atividade experimental problematizada (AEP) como uma estratégia pedagógica para o ensino de ciências: aportes teóricos, metodológicos e exemplificação. Experiências em Ensino de Ciências, v. 12, n. 5, 2017.

SILVA, A. L. S.; MOURA, P. R. G.; DEL PINO, J. C. Subsídios pedagógicos e epistemológicos da atividade experimental problematizada. Revelli, v. 10, n. 4, dez. 2018.

SILVA, A. L. S.; FERREIRA, M.; PEREIRA, S. M.; FILHO, O. L. S. Atividade experimental problematizada (AEP): revisão bibliográfica em descritores na área de ensino de ciências. Revista Pesquisa e Debate em Educação, v. 9, n. 1, 2019.

SILVA, A. L. S.; NOGARA, P. A. Atividade Experimental Problematizada (AEP) - 60 experimentações com foco no ensino de química: da educação básica à universidade. Curitiba, PR: Appris, 2018.

SILVA, A. L. S.; MOURA, P. R. G. Ensino experimental de ciências - uma proposta: atividade experimental problematizada (AEP). São Paulo, SP: Livraria da Física, 2018.

SOARES, A. C.; LOGUERCIO, R. Q. Outros espaços de aprendizagem: da máscara aos saberes sobre ciências. Revista Contexto \& Educação, 32(101), p. 125-141, 2017. DOI: https://doi.org/10.21527/21791309.2017.101.125-141

VAN FRAASSEN, B. The scientific image. Oxford: Clarendon Press, 1980. 